\section{() OPEN ACCESS}

\title{
Faecal immunochemical testing (FIT) in symptomatic patients: what are we missing?
}

\author{
Alexia Farrugia (D) , 1,2 Monika Widlak, ${ }^{2,3}$ Charles Evans, ${ }^{1}$ \\ Stephen Charles Smith, ${ }^{4,5}$ Ramesh Arasaradnam ${ }^{2,3}$
}

\begin{abstract}
'Department of Surgery, University Hospitals Coventry and Warwickshire NHS Trust, Coventry, UK

${ }^{2}$ Warwick Medical School, University of Warwick, Warwick Medical School, Coventry, UK

${ }^{3}$ Department of Gastroenterology, University Hospitals Coventry and Warwickshire NHS Trust, Coventry, UK

${ }^{4}$ Department of Clinical Biochemistry, University Hospitals Coventry and Warwickshire NHS Trust, Coventry, UK

${ }^{5}$ Midlands and North West Bowel Cancer Screening Hub, Coventry, UK
\end{abstract}

\section{Correspondence to}

Dr Ramesh Arasaradnam, Department of Gastroenterology, University Hospitals Coventry and Warwickshire NHS Trust, Coventry, UK; R.Arasaradnam@ warwick.ac.uk

Received 28 December 2018 Revised 9 April 2019

Accepted 18 April 2019 Published Online First

11 May 2019

\section{Check for updates}

(C) Author(s) (or their employer(s)) 2020. Re-use permitted under CC BY-NC. No commercial reuse. See rights and permissions. Published by BMJ.

To cite: Farrugia $\mathrm{A}$

Widlak M, Evans C, et al.

Frontline Gastroenterology

2020;11:28-33.

\begin{abstract}
Objective Faecal immunochemical test (FIT) shows promise as a non-invasive triage test for colorectal cancer (CRC) in the symptomatic population. The aim of this study was to assess the use of FIT within the recent NG12 and DG30 National Institute for Health and Care Excellence (NICE) guidelines.

Design A single-centre prospective study of patients referred to University Hospitals Coventry and Warwickshire NHS Trust via the 2-week wait (TWW) pathway between January 2015 and March 2016 was conducted. 612 patients were reviewed, of which 519 were found to meet the NG12 criteria and 79 met the DG30 criteria. Data included age, sex, symptoms, colonoscopy or CT colonography, histology and FIT results.
\end{abstract}

Main outcome measures FIT was performed in all patients and sensitivity, specificity, positive predictive value and negative predictive value, with 95\% Cl, for cancers and adenomas within each pathway (TWW, NG12 and DG30) was calculated.

Results CRC sensitivity in TWW pathway patients, NG12 and DG30 group was $86.84 \%$ (95\% Cl $71.91 \%$ to $95.59 \%), 84.85 \%$ (95\% Cl $68.1 \%$ to $94.89 \%$ ) and $100 \%$ (95\% Cl $47.82 \%$ to $100 \%)$, respectively. Specificity was $82.23 \%$ (95\% Cl $78.85 \%$ to $85.27 \%$ ), $81.28 \%$ (95\% $\mathrm{Cl} 77.52 \%$ to $84.65 \%)$ and $91.89 \%(95 \% \mathrm{Cl}$ $83.18 \%$ to $96.97 \%)$, respectively. Adenoma sensitivity in the groups was $30.69 \%(95 \% \mathrm{Cl}$ $29.9 \%$ to $40.66 \%), 30.77 \%(95 \% \mathrm{Cl} 21.51 \%$ to $41.32 \%$ ) and $25 \%$ (95\% Cl $3.19 \%$ to $65.09 \%$ ), respectively.

Conclusion Use of FIT within the remit of the NG12 NICE guidelines shows a high sensitivity and specificity and may be an effective triage tool when considering whether to perform investigations. However, there is still a miss rate. FIT within DG30 has excellent sensitivity and improved specificity; however, DG30 targets lower risk groups and accounts for only $13 \%$

\section{Summary box}

What is already known about this topic?

- Faecal immunochemical test (FIT) is a promising non-invasive diagnostic test for colorectal cancer (CRC) in symptomatic population.

What does this study add?

- Use of FIT within the recent National Institute for Health and Care Excellence (NICE) guideline DG30 shows a high sensitivity and specificity and may be an effective triage tool when considering whether to perform investigations.

How might this impact on clinical practice in the foreseeable future? - The risk of missing CRC remains despite of applying the NG12 criteria with FIT, and therefore another marker may be required.

of the entire referrals for suspected cancer.

Therefore, managing the larger, higher risk NG12 group may require the addition of another test or marker to ensure that CRC is not missed.

\section{INTRODUCTION}

Faecal immunochemical test (FIT) holds promise as a non-invasive diagnostic tool to exclude colorectal cancer (CRC) in both symptomatic and screening populations. It is based on detection of human haemoglobin $(\mathrm{Hb})$ moiety in faeces. ${ }^{1}$ There is increasing evidence of its use with support from a recent systematic review ${ }^{23}$ and national guidelines. ${ }^{4}$

Although the test appears promising, there are concerns with regard to the false negative results and the risk of missing $\mathrm{CRC}$ in these patients. Hence, ongoing 
debate continues as to how to apply this test in accordance with the National Institute for Health and Care Excellence (NICE) guidelines. The current 2-week wait (TWW) referral pathway implemented by the UK Department of Health in 2000 was meant to streamline patients suspected of having cancer, in the most effective manner. However, as this is predicated on symptoms, signs and blood tests, resulting in only $12 \%$ of all CRC detected through this pathway ${ }^{5}$ and only $9 \%$ of TWW referrals resulted in the detection and treatment of CRC. ${ }^{6}$ The NG12 guideline (2015) recommends referral via the TWW pathway if occult blood is found in faeces on testing by the guaiac method. ${ }^{7}$ This guideline was subsequently updated to replace guaiac faecal occult blood test with FIT in the July 2017 (DG30). ${ }^{8}$ It recommends FIT testing if patients do not have overt rectal bleeding but have unexplained symptoms which still do not meet the criteria for referral via the TWW pathway, that is, low risk of CRC. The threshold for result reporting is $10 \mu \mathrm{g}$ of $\mathrm{Hb} / \mathrm{g}$ of faeces, and if positive, patients should then be referred via the TWW pathway for suspected cancer.

The aim of this study was to compare the diagnostic accuracy of FIT in patients referred within a single centre by TWW pathway (all comers) and its utility in line with guidance from NICE 2015 (NG12) and the new NICE 2017 (DG30) guidelines. ${ }^{78}$

\section{METHODS}

This was a tertiary single-centre prospective study which took place at University Hospitals Coventry and Warwickshire NHS Trust via the national TWW pathway. The study was conducted between January 2015 and March 2016 and inclusion criteria were symptomatic patients referred through the national TWW pathway who had FIT during that time frame. Those who did not have complete colonic investigations or deemed unfit for investigations were excluded. FIT was measured by the HM-JACKarc automated system (Kyowa Medex Co. Ltd, Tokyo, Japan) and a cut-off of $10 \mu \mathrm{g}$ of $\mathrm{Hb} / \mathrm{g}$ of faeces as per NICE DG30 guidelines was applied for this analysis. ${ }^{89}$

Demographic data collected included age, sex, symptoms, FIT, colonoscopy or CT colonography and histology results. The patients were compared according to the symptoms meeting the TWW pathway, NG12 and DG30 criteria (table 1). All patients in the 'parent' group (TWW pathway) were individually assessed to determine whether they met the criteria defined by the NG12 or the DG30 guidelines. This is shown in figure 1 . The NG12 guideline states that patients over the age of 40 with unexplained weight loss and abdominal pain, patients over 50 with unexplained rectal bleeding and patients over 60 with iron deficiency anaemia and change in bowel habit should all be referred for suspicion of CRC. This pathway also advises referral for any patients with a rectal or abdominal mass, patients with tests showing occult blood in their faeces, and patients under 50 with rectal bleeding and either abdominal pain, change in bowel habit, weight loss or iron deficiency anaemia. ${ }^{7}$ The DG30 guideline advises when to test for faecal occult blood using FIT testing at a threshold of $10 \mu \mathrm{g} \mathrm{Hb} / \mathrm{g}$ faeces, which is in all patients without rectal bleeding who have unexplained symptoms but do not meet the criteria for a suspected cancer referral pathway. ${ }^{8}$

The sensitivity, specificity, positive predictive value (PPV) and negative predictive value (NPV) of FIT in three groups were calculated for CRC and adenoma, with a CI of 95\% (table 2). Patients with high-grade dysplasia (HGD) were included in the cancer group as they were considered high risk. The t-test, $\chi^{2}$ test and Fisher's exact test were carried out to assess statistical significance as appropriate. Statistical analysis was carried out using Microsoft Excel 365 and IBM SPSS Statistics V.23.

\section{RESULTS}

A total of 612 patients referred via the TWW pathway were included in the study. The reasons for referral are shown in table 1 . Five hundred and nineteen patients fulfilled the NG12 criteria and 79 fulfilled the DG30 criteria (low risk) for referral.

Fourteen patients (six men and eight women with mean age of 43.2 years) referred via the TWW system did not fit into either criteria-NG12 or DG30. All of these patients were referred with per rectal (PR) bleeding but did not fit the criteria for NG12 due to lack of abdominal pain, change of bowel habit, weight loss or iron deficiency anaemia. The median FIT was $2.5 \mu \mathrm{g} \mathrm{Hb} / \mathrm{g}$ faeces. Of these 14 patients who did not fit into either criteria (NG12 or DG30), two patients had low-risk adenoma $(<10 \mathrm{~mm})$ and only one of these patients had a FIT value $>10 \mu \mathrm{g} \mathrm{Hb} / \mathrm{g}$ faeces. None of these patients had cancer.

Though the median FIT is lower in the DG30 group (table 1), there was no significant difference in median FIT levels between patients meeting the NG12 criteria and those who meet DG30 criteria $(\mathrm{p}=0.073)$. A total of $477(77.9 \%)$ patients were FIT negative within the TWW group at a cut-off level of $<10 \mu \mathrm{g} \mathrm{Hb} / \mathrm{g}$ faeces.

\section{Colorectal cancer}

Thirty-five patients had CRC and three had HGD. Ten lesions were right sided, and eight of these were FIT positive (80\%). Median FIT for the right-sided group was 93.9 (16.7-155.2) $\mu \mathrm{g} \mathrm{Hb} / \mathrm{g}$ faeces and only one patient had presented with rectal bleeding. The other 28 lesions were left sided, of which 17 (60\%) had presented with rectal bleeding and 25 were FIT positive (89.3\%). Median FIT for left-sided malignancies was significantly higher at $490.2(146.5-1000)$ $\mu \mathrm{g} \mathrm{Hb} / \mathrm{g}$ faeces compared with 93.9 (16.7-155.2) $\mu \mathrm{g}$ $\mathrm{Hb} / \mathrm{g}$ faeces on the right $(\mathrm{p}<0.001)$. This has previously been described. ${ }^{10}$ There was no significant difference in median FIT levels between cancers picked up 
Table 1 Clinical demographics of patients fulfilling the TWW criteria, NG12 and DG30 and characteristics of the CRC identified and missed grouped by criteria; TWW (all comers), NG12 and DG30

\begin{tabular}{|c|c|c|c|}
\hline & TWW (N=612) & NG12 (N=519) & DG30 (N=79) \\
\hline Age (mean) & 66.4 & 68.6 & 56.1 \\
\hline \multicolumn{4}{|l|}{ Sex } \\
\hline Male & 300 & 254 & 38 \\
\hline Female & 312 & 265 & 41 \\
\hline \multicolumn{4}{|l|}{ Symptoms } \\
\hline Rectal bleeding & 244 & 230 & 0 \\
\hline Abdominal pain & 175 & 158 & 19 \\
\hline Change in bowel habit & 390 & 349 & 40 \\
\hline Weight loss & 91 & 84 & 7 \\
\hline Anaemia, including iron deficiency & 117 & 94 & 25 \\
\hline Abdominal/rectal mass & 10 & 10 & 0 \\
\hline Family history of CRC & 119 & 104 & 12 \\
\hline FIT median (IQR); $\mu \mathrm{g} \mathrm{Hb} / \mathrm{g}$ faeces & $1.89(1-7.48)$ & $1.9(1-8.3)$ & $1.6(0.9-2.6)$ \\
\hline Patients with cancer ( $\mathrm{N}=38$ ) & TWW (N=38) & NG12 (N=33) & DG30 (N=5) \\
\hline \multicolumn{4}{|l|}{ Symptoms } \\
\hline Rectal bleeding & 18 & 18 & 0 \\
\hline Abdominal pain & 17 & 13 & 4 \\
\hline Change in bowel habit & 23 & 23 & 0 \\
\hline Weight loss & 8 & 8 & 0 \\
\hline Anaemia, including iron deficiency & 6 & 3 & 3 \\
\hline Abdominal/rectal mass & 10 & 10 & 0 \\
\hline Family history of CRC & 4 & 4 & 0 \\
\hline Median FIT (IQR); $\mu \mathrm{g} \mathrm{Hb/g}$ faeces & $261.5(104.4-910)$ & $256.9(100.55-906.33)$ & $\begin{array}{l}266.1(199.25- \\
633.5)\end{array}$ \\
\hline Missed CRC; FIT negative $(\mathrm{N}=5)$ & TWW (N=5) & NG12 (N=5) & DG30 $(\mathrm{N}=0)$ \\
\hline Site $R / L$ & $2 / 3$ & $2 / 3$ & 0 \\
\hline Anaemia (\%) & $3(60 \%)$ & $3(60 \%)$ & 0 \\
\hline Mass & $2(40 \%)$ & $2(40 \%)$ & 0 \\
\hline Weight loss & $4(80 \%)$ & $4(80 \%)$ & 0 \\
\hline Median FIT (IQR); $\mu \mathrm{g} \mathrm{Hb/g}$ faeces & $2.5(1.1-5.7)$ & $2.5(1.1-5.7)$ & N/A \\
\hline
\end{tabular}

CRC, colorectal cancer; FIT, faecal immunochemical test; Hb, haemoglobin; TWW, 2-weeks wait.

by NG12 and those detected by DG30 ( $\mathrm{p}=0.843)$ via a Mann-Whitney U test (table 1). The sensitivity, specificity, PPV and NPV for CRC are shown in table 2. Receiver operator characteristic (ROC) curves for CRC within the TWW, NG12 and DG30 groups are

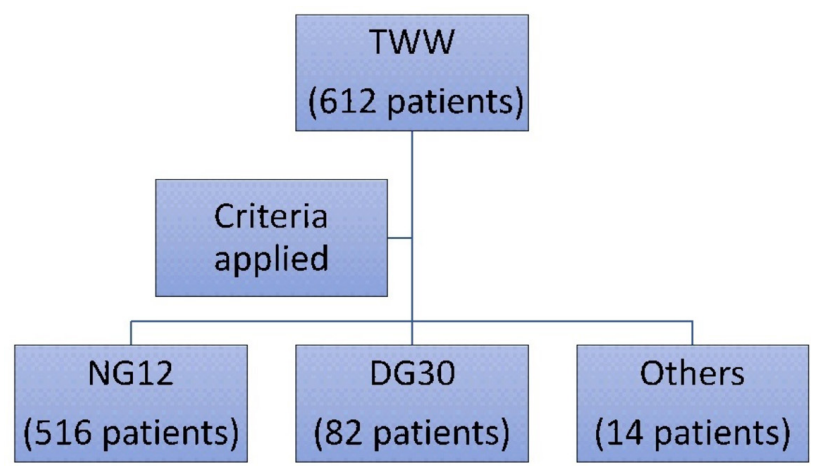

Figure 1 Patient flow diagram. shown in figure 2. There was no statistical significance in the difference in sensitivity and specificity the NG12 and DG30 when compared with the TWW ( $\mathrm{p}=0.382$; $\mathrm{p}=0.706$ ).

Within the TWW group, five CRC were missed, of which all were missed within the NG12 pathway when using FIT at the cut-off $\geq 10 \mu \mathrm{g} \mathrm{Hb} / \mathrm{g}$. Of the 38 malignant cases (35 cancers and three HGD) picked up by TWW, 33 fit into the NG12 (25 left-sided and eight right-sided) and five would fit the DG30 pathway. All of the malignant cases identified by DG30 would have been missed using NG12 but not within TWW group (all comers). Most of these patients were either aged less than 50 years or presented with less alarming symptoms such as abdominal pain which was not accompanied by rectal bleeding. This is shown in table 1 .

\section{Colorectal adenomas}

One hundred and one out of $612(16.5 \%)$ patients were diagnosed with adenomas. Of these, 91 fit the 
Table 2 Sensitivity, specificity, NPV and PPV of FIT for CRC and adenoma within TWW, NG12 and DG30 pathways

\begin{tabular}{llll}
\hline CRC & TWW (N=612) (95\% CI) & NG12 (N=519) (95\% CI) & DG30 (N=79) (95\% CI) \\
\hline Sensitivity & $86.84 \%(71.91 \%$ to $95.59 \%)$ & $84.85 \%(68.1 \%$ to $94.89 \%)$ & $100 \%(47.82 \%$ to $100 \%)$ \\
Specificity & $82.23 \%(78.85 \%$ to $85.27 \%)$ & $81.28 \%(77.52 \%$ to $84.65 \%)$ & $91.89 \%(83.18 \%$ to $96.97 \%)$ \\
NPV & $98.95 \%(97.66 \%$ to $99.53 \%)$ & $98.75 \%(97.23 \%$ to $99.44 \%)$ & $100 \%$ \\
\hline PPV & $24.44 \%(20.69 \%$ to $28.63 \%)$ & $23.63 \%(19.57 \%$ to $28.01 \%)$ & $45.45 \%(27.9 \%$ to $64.22 \%)$ \\
\hline Adenoma & TWW (N=612) $(95 \% \mathrm{CI})$ & $\mathrm{NG} 12(\mathrm{~N}=519)(95 \% \mathrm{Cl})$ & DG30 (N=19) $(95 \% \mathrm{Cl})$ \\
\hline Sensitivity & $30.69 \%(21.9 \%$ to $40.66 \%)$ & $30.77 \%(21.51 \%$ to $41.32 \%)$ & $25.00 \%(3.19 \%$ to $65.09 \%)$ \\
Specificity & $79.65 \%(75.89 \%$ to $83.06 \%)$ & $78.8 \%(74.82 \%$ to $82.79 \%)$ & $86.48 \%(75.27 \%$ to $92.44 \%)$ \\
NPV & $85.32 \%(83.53 \%$ to $86.96 \%)$ & $87.17 \%(82.13 \%$ to $86.01 \%)$ & $91.43 \%(87.61 \%$ to $94.15 \%)$ \\
\hline PPV & $22.96 \%(17.51 \%$ to $29.51 \%)$ & $23.93 \%(18.01 \%$ to $86.01 \%)$ & $16.66 \%(5.02 \%$ to $43.1 \%)$ \\
\hline
\end{tabular}

CRC, colorectal cancer; FIT, faecal immunochemical test; NPV, negative predictive value; PPV, positive predictive value; TWW, 2-week wait.

NG12 pathway while only eight fit into DG30. Again, all those in the DG30 pathway were missed by NG12 due to the vital differences in the criteria for referral in the two pathways. Two adenomas would have been missed as the patients were aged less than 50 years and had rectal bleeding with no other suspicious symptoms, thus not being identified by either pathways. ROC curves for adenoma within the TWW, NG12 and DG30 groups are shown in figure 3 . The characteristics of the test for adenoma are shown in table 2.

Eighteen adenomas were larger than $10 \mathrm{~mm}$, of which six were low-grade tubulovillous adenomas. Twelve of these patients were FIT positive. The rest were classified as tubular adenomas. One polyp $<9$ $\mathrm{mm}$ was classified as low-grade tubulovillous adenoma. All the rest were low-grade tubular adenomas and one was classified as sessile serrated polyp.

\section{DISCUSSION}

The aim of this study was to investigate diagnostic accuracy of FIT within the TWW, NG12 and DG30 pathways and assess whether its introduction across the board could help in reducing colonic investigations. At this point, NICE only recommends FIT within the DG30 pathway, which only includes patients who do not fill the NG12 criteria and would otherwise not be referred. We are therefore using this as a starting point to expand the role of FIT in symptomatic population suspected of CRC. Several studies have reported role of FIT in all comers (TWW) group ${ }^{10} 11$ and directly from primary care. ${ }^{12}$

The DG30 pathway is targeting lower risk groups hence a smaller cohort. The patients with cancer who fit the DG30 pathway had predominantly vague symptoms such as abdominal pain with or without change in bowel habit, which is why they would not have been referred via NG12. When reviewing the overall TWW pathway data, a large number of patients did not meet the NG12 criteria due to the age restrictions imposed, although they still had suspicious symptoms such as change in bowel habit and anaemia (table 1).

Regardless of pathways applied, FIT might miss patients with CRC. As per NICE, the threshold of $10 \mu \mathrm{g} \mathrm{Hb} / \mathrm{g}$ of faeces has been applied, ${ }^{8}$ and while lowering the threshold will improve the sensitivity of the test, there is a risk of higher false positives. This will impact on policy holders as lowering the threshold for suspicion may increase the number of patients undergoing invasive testing; thus, the decision must be made as to whether a higher sensitivity or specificity is preferred in this population where the prevalence of $\mathrm{CRC}$ is around $6 \% .{ }^{1011}$

Our data shows that for CRC, the highest sensitivity and specificity is within DG30, though there is
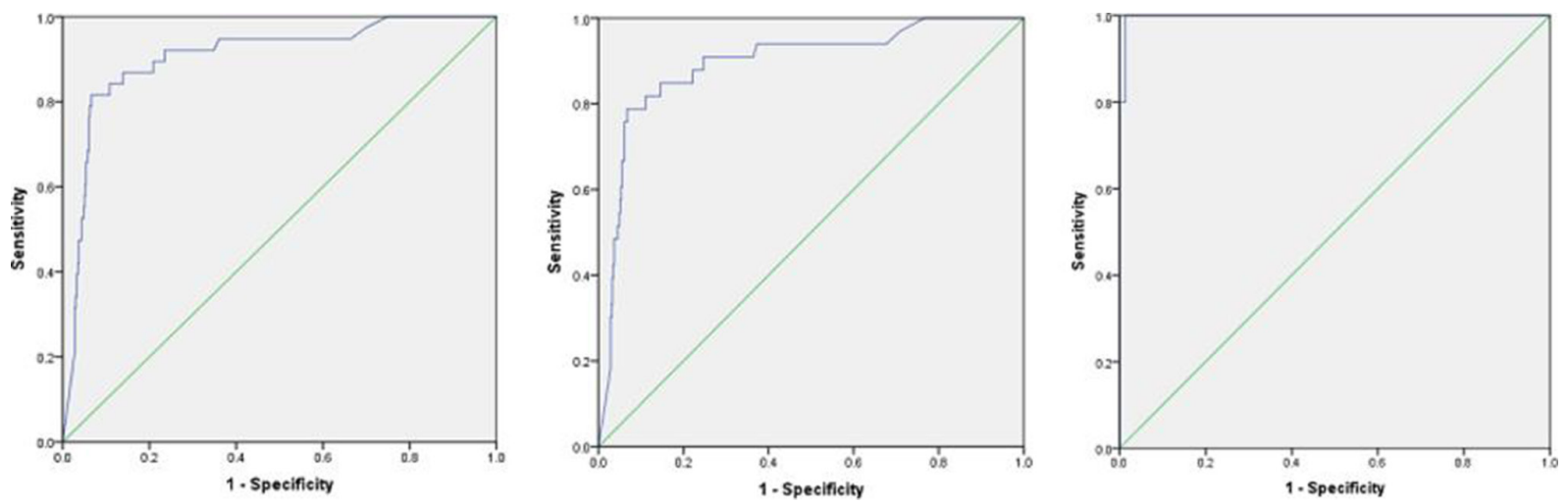

Figure 2 Receiver operator curves for (A) 2-week wait (sensitivity 86.84\%; specificity 82.23\%), (B) NG12 (sensitivity 84.85\%; specificity $81.28 \%$ ) and (C) DG30 (sensitivity 100\%; specificity $91.89 \%$ ) for colorectal cancer. 
A

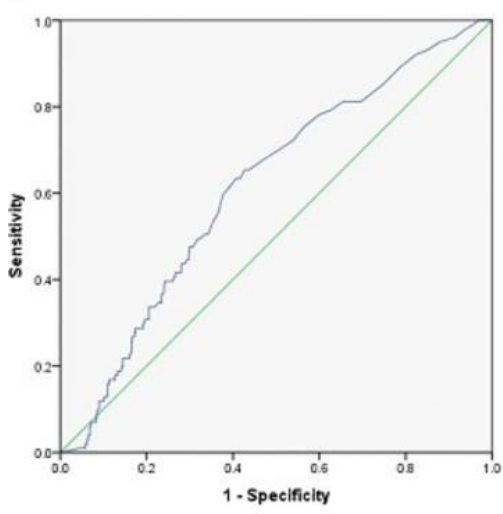

B

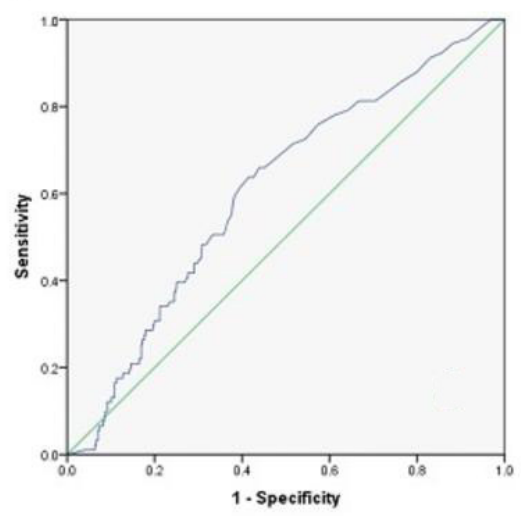

C

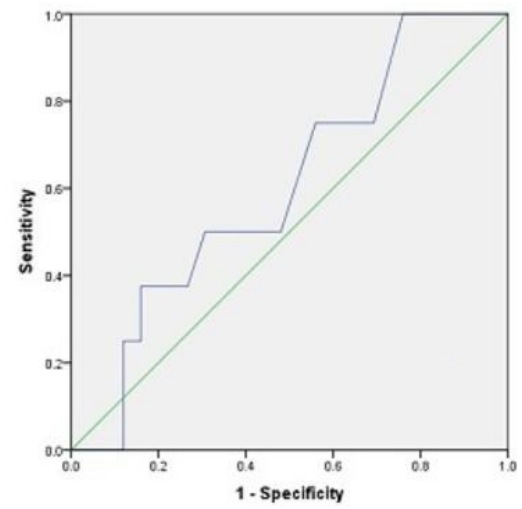

Figure 3 Receiver operator curves for (A) TWW (sensitivity 30.69\%; specificity 79.65\%), (B) NG12 (sensitivity 30.77\%; specificity 78.8\%) and (C) DG30 (sensitivity $25 \%$; specificity $86.48 \%$ ) for adenomas.

no significant difference in sensitivity and specificity between the TWW/NG12 and TWW/DG30 or NG12/ DG30 pathways $(p=0.382, p=0.706, p=0.226$, respectively). This may imply that FIT negative patients within these pathways could avoid colonic investigations. A negative FIT test may 'rule out' a cancer diagnosis in such cases. The high NPVs across the board suggest that in those that are FIT negative, colon cancer can be reasonably excluded. However, the low PPVs suggest that a raised FIT value does not necessarily predict the likelihood of colon cancer. The highest PPV within the DG30 pathway implies that a raised FIT within this pathway should be investigated and given due diligence. The fact that the NPV is similar across all the pathways may imply that as FIT is recommended within DG30, then it should also be recommended for use within the other pathways to aid in determining which patients require further investigation.

Of the 477 FIT negative patients in the TWW group, there were five FIT negative cancers (ie, false negative FIT tests), but they would still have been referred via NG12 as they fit the criteria for referral due to their symptoms. These false negative cases would imply a slight risk of missing such cases if colonic investigations were not performed; however, the importance of assessing each clinical case based on its own merits cannot be overstated. The high number of true negatives implies that introducing FIT within the pathways may ease the burden of investigations performed. Cases such as these also raise the question, once again, of possibly expanding the referral criteria in the guidelines to decrease the effect of false negatives on diagnosis of CRC.

FIT performs less well in patients who were found to have adenoma, which is a recognised phenomenon. Coupled with the fact that adenoma detection is already lower than expected in a symptomatic population (16\% vs $30 \%)$ (unpublished local data) further affirms that FIT on its own is insufficiently sensitive for adenoma detection at the standard threshold (10 $\mu \mathrm{g} \mathrm{Hb} / \mathrm{g}$ faeces). FIT missed even some of the 'highrisk' adenomas $(>10 \mathrm{~mm})$ which is understandable as not all adenomas bleed. Thus, we conclude that FIT on its own within symptomatic patients suspected of adenoma is not applicable, as it does not adequately manage the risk associated with these adenomas.

Of note, 261 patients had a completely normal colonoscopy or CT colonography of which 237 (91\%) were FIT negative with mean age of 62 years. This amounts to $42 \%$ of the total study population, and may imply that at least this proportion of individuals could potentially avoid investigations.

\section{CONCLUSION}

The use of FIT within DG30 has shown the most optimal sensitivity and specificity, despite these not being statistically significant. This is expected as this pathway targets a relatively lower risk group than the overall population referred for colonic investigations, but it accounts for only $13 \%$ of the entire referrals for suspected cancer. Guidance for use of FIT within higher risk population pathways such as NG12 and TWW has not been addressed, though we have shown that it may be an effective triage tool when considering whether to perform investigations. There is a false negative rate with using FIT on its own at the standard threshold of $10 \mu \mathrm{g} \mathrm{Hb} / \mathrm{g}$ faeces but reducing this further may not reduce unnecessary investigations, hence the need for additional specific markers. ${ }^{11}$ However, as we have shown that a significant number of FIT negative patients have negative colonoscopy or CT colonoscopy, the inclusion of markers such as FIT within the pathways would still assist in the decisionmaking process of whether referral for investigation is appropriate.

Contributors AF contributed to data analysis and writing of the manuscript. MW led the FAMISHED 2WW project, recruited patients and collected data. SCS supervised FIT laboratory analysis. RA obtained funding. CE and RA planned the study. MW, CE, SCS and RA reviewed the manuscript.

Funding BDRF as part of the FAMISHED study. 
Competing interests None declared.

Patient consent for publication Not required.

Provenance and peer review Not commissioned; externally peer reviewed.

Data sharing statement Data are available upon reasonable request.

Open access This is an open access article distributed in accordance with the Creative Commons Attribution Non Commercial (CC BY-NC 4.0) license, which permits others to distribute, remix, adapt, build upon this work noncommercially, and license their derivative works on different terms, provided the original work is properly cited, appropriate credit is given, any changes made indicated, and the use is noncommercial. See: http://creativecommons.org/licenses/by-nc/4. $0 /$.

\section{ORCID iD}

Alexia Farrugia http://orcid.org/0000-0002-4366-9068

\section{REFERENCES}

1 Passamonti B, Malaspina M, Fraser CG, et al. A comparative effectiveness trial of two faecal immunochemical tests for haemoglobin (fit). Assessment of test performance and adherence in a single round of a population-based screening programme for colorectal cancer. Gut 2018;67:485-96.

2 Westwood M, Corro Ramos I, Lang S, et al. Faecal immunochemical tests to triage patients with lower abdominal symptoms for suspected colorectal cancer referrals in primary care: a systematic review and cost-effectiveness analysis. Health Technol Assess 2017;21:1-234.

3 Chandrapalan SSJ, Woolley D, Arasaradnam RP. Systematic review and meta-analysis: diagnostic accuracy of faecal immunochemical testing for haemoglobin (fit) in detecting colorectal cancer for both symptomatic and screening population. Acta Gastro-enterologica Belgica. In Press 2019.

4 Arasaradnam RP, Brown S, Forbes A, et al. Guidelines for the investigation of chronic diarrhoea in adults: british society of gastroenterology, 3rd edition. Gut 2018;67:1380-99.

5 Salika T, Abel GA, Mendonca SC, et al. Associations between diagnostic pathways and care experience in colorectal cancer: evidence from patient-reported data. Frontline Gastroenterol 2018;9:241-8.

6 Mozdiak E, Tsertsvadze A, McFarlane M, et al. The effect of the 2-week wait referral system on the detection of and mortality from colorectal cancer: protocol of a systematic review and meta-analysis. Syst Rev 2016;5.

7 NICE. Suspected cancer: recognition and referral. National Institute for Health and Care Excellence, 2015.

8 NICE. Quantitative faecal immunochemical tests to guide referral for colorectal cancer in primary care. National Institute for Health and Care Excellence, 2017.

9 Godber IM, Todd LM, Fraser CG, et al. Use of a faecal immunochemical test for haemoglobin can aid in the investigation of patients with lower abdominal symptoms. Clin Chem Lab Med 2016;54:595-602.

10 Widlak MM, Thomas CL, Thomas MG, et al. Diagnostic accuracy of faecal biomarkers in detecting colorectal cancer and adenoma in symptomatic patients. Aliment Pharmacol Ther 2017;45:354-63.

11 Widlak MM, Neal M, Daulton E, et al. Risk stratification of symptomatic patients suspected of colorectal cancer using faecal and urinary markers. Colorectal Dis 2018;20:O335O342.

12 Mowat C, Digby J, Strachan JA, et al. Faecal haemoglobin and faecal calprotectin as indicators of bowel disease in patients presenting to primary care with bowel symptoms. Gut 2016;65:1463-9. 